\title{
El agua, una clave en la relación sino-india
}

Lic. María Mercedes Solé ${ }^{1}$

\section{Contribución en la Sección Política Internacional}

Existen abundantes ejemplos de conflictos e invasiones provocados por la escasez de los recursos naturales, a lo largo de la historia. Antiguamente, los países más poderosos salían en busca de estas riquezas, especialmente oro, diamantes, petróleo, madera y tierras cultivables. Sin embargo, el agua, no había sido considerada una causa de tensión y rivalidad, a diferencia de lo que sucede actualmente, convirtiéndose en un asunto de seguridad internacional y en una cuestión esencial en la agenda de casi todos los gobiernos (Nieto, 2011).

Siendo un recurso clave, dado que es necesaria para toda forma de vida: humanos, animales, y plantas, sólo el 3\% del agua de la Tierra es potable y su demanda se incrementa día a día. Para 2025, se estima que dos tercios de la población mundial vivirá en países con escasez moderada o severa de agua (Mingst, 2009).

En ese contexto dado, en la región del Himalaya, China e India están compitiendo por valiosos recursos hidroeléctricos y de agua en el río Yarlung Tsangpo-Brahmaputra (Tenzin, 2015). El Yarlung Zangbo es el mayor río del Tibet, cuyo origen está en el glaciar de Jiemayangzong, en el territorio del distrito Zhongba, al pie norte del Himalaya. Al pasar por la prefectura de Luoyu, entra en la India, donde se inicia el río Brahmaputra (Embajada de la República Popular China en la República Oriental del Uruguay, 2007).

Ya como Brahmaputra, prosigue hasta Bangladesh donde, unido al Ganges, desemboca formando un extenso delta en el golfo de Bengala (Fayanás, 2010). A pesar de que, los sistemas fluviales del Ganges y el Brahmaputra abarcan menos del 0,2\% de las tierras del planeta, son habitados por el 10\% de la humanidad (Fayanás, 2010).

Un dato importante, que agrega interés a la cuestión, es que un $60 \%$ de la población mundial vive en Asia (4.400 millones), siendo, China, con 1.400 millones, e India, con 1.300 millones, los países con mayor cantidad de habitantes del planeta, representando ellos el $19 \%$ y $18 \%$ de la población mundial, respectivamente (Naciones Unidas, 2017).

A esta presión per cápita de cantidad de habitantes, se le suma el gran desarrollo económico que tuvieron ambas naciones, lo que conlleva nuevas necesidades

\footnotetext{
${ }^{1}$ Licenciada en Periodismo (UP) y miembro del Grupo de trabajo sobre India y Asia del Sur, del Comité de Asuntos Asiáticos, del Consejo Argentino para las Relaciones Internacionales.
} 
energéticas, de materias primas y sobre todo de agua, motivo por el cual, la crisis hídrica crece con la misma rapidez que la economía (Fayanás, 2010).

Los ríos del Tíbet han permanecido por mucho tiempo sin ser aprovechados, a causa de la dificultad del terreno, pero, con los avances tecnológicos desarrollados en la última década, los líderes chinos se embarcaron en grandes proyectos de construcción de represas. Algunas de ellas, además de generar energía hidroeléctrica, serán parte de un masivo plan de desviación de ríos hacia el norte árido (Krishnan, 2009).

Esta iniciativa afectará directamente a la India, razón por la cual, se generó un clima de tensión y preocupación en la población, que aumentó cuando el gobierno chino anunció planes para comenzar la construcción de la represa hidroeléctrica de Zangmu, situada en el curso medio del río Yarlung-Tsangpo. Ello produjo, versiones que hablaban del comienzo de un importante proyecto de desviación de ríos, que secaría el río Brahmaputra, especulación que creció aún más por la negativa de China a divulgar información considerada como "asuntos internos" (Tenzin,2015).

Sin embargo, en 2008, el Primer Ministro Manmohan Singh visitó Pekín, y a pesar de hacer presente su preocupación por el proyecto, su accionar se desarrolló bajo la lógica de "confiar, pero verificar", siendo que hasta el momento (según imágenes satelitales) no se había registrado ningún indicio de actividades relacionadas a la represa (Caula y Iribarne, 2010).

Finalmente, en 2014, la represa de Zangmu, primera central hidroeléctrica en el río Yarlung Zangbo, comenzó a funcionar, a 3.300 metros de altura sobre el nivel del mar, en la región del Tíbet, luego de cinco años de obras (Krishnan, 2014).

El mismo año, ya en el gobierno, el Primer Ministro Narendra Modi, recibió la aprobación para avanzar en la realización de otro proyecto hidroeléctrico de 3,000 megawatios, sobre el río Dibang -uno de los grandes tributarios del Brahmaputra-, entre los muchos de este tenor que India posee, en la búsqueda de producir 57.000 megawatios de hidroelectricidad en los estados de Assam y Arunachal Pradesh (este último, también objeto de disputa entre China e India), en la zona noreste del país, que es considerada en el ámbito político local, como un futuro centro neurálgico de India y un lugar relevante en el programa nacional de construcción de represas (Duarah, 2014).

Asimismo, recientemente fue anunciada una gran obra de ingeniería por parte de China, que consiste en la construcción de un túnel de 1.000 kilómetros, que se convertiría en el acueducto subterráneo más largo del mundo. El plan consiste en que se transporte agua del río Yarlung Zangbo hasta el desierto de Taklamakán (Chen, 2017), lo que podría 
provocar resultados catastróficos aguas abajo, afectando directamente tanto a India como a Bangladesh (Balachandran, 2017; Indian Defense News, 2017).

Dada la naturaleza histórica y política del vínculo sino-indio y su relevancia para la estabilidad del continente asiático, las estrategias en torno a los recursos hídricos compartidos se inscriben en un contexto de particular importancia, teniendo a la meseta tibetana como un eje central a la hora de discutir cuestiones importantes, tales como el futuro hídrico de ambos países, vínculo en el que aún subsisten tensiones relacionadas a disputas territoriales y otras situaciones conflictivas.

A más de ello, cabe recalcar que los estados en cuestión se encuentran en el marco de una ausencia de tratados, organizaciones, grupos o comisiones de trabajo que regulen el manejo compartido de la cuenca, lo que genera un vacío institucional, que debe ser saldado para colaborar con la solución de posibles tensiones bilaterales y la firma de futuros acuerdos (Caula y Iribarne, 2011).

Mientras para algunos autores la distribución de los recursos puede terminar en grandes conflictos entre las dos potencias asiáticas, para otros, seguirá primando la paz. Todo dependerá de las voluntades y actuaciones de ambos países, en torno del uso de los recursos y la creciente demanda energética, mientras el tema agrega otro punto de tensión en la zona, que convoca, otra vez, todas las miradas.

\section{Referencias}

Balachandran, M (2017). China's planning a 1,000km tunnel to divert water away from one of India's largest rivers. Quartz India (30 de octubre). Recuperado de https://qz.com/1114843/chinas-grand-plan-for-the-brahmaputra-a-1000km-tunnelto-divert-water-away-from-tibet/

Caula, D., \& Iribarne, V. (2010). La escasez de los recursos hídricos en el Siglo XXI. Estrategias de China e India: ¿Cooperación o Conflicto?. Octava jornada de Medio Oriente. Simposio en el V Congreso de Relaciones Internacionales, IRI, UNLP, La Plata, Argentina (24-26 de noviembre). Recuperado de http://www.iri.edu.ar/publicaciones_iri/IRI\%20COMPLETO\%20-

\%20Publicaciones-

V05/Publicaciones/cd\%20V\%20congreso/ponencias/0\%20Caula_Iribarne_La\%2 Oescasez\%20de\%20los\%20recursos.pdf

(2011). ¿Cooperación o Conflicto? China e India ante la escasez de recursos hídricos. Argentina: Grupo de Estudios Internacionales Contemporáneos. Recuperado de https://geic.files.wordpress.com/2011/04/ai-006-20111.pdf 
Chen, S. (2017). Chinese engineers plan 1,000km tunnel to make Xinjiang desert bloom. South China Morning Post/Society (29 de octubre). Recuperado de http://www.scmp.com/news/china/society/article/2116750/chinese-engineers-plan$1000 \mathrm{~km}$-tunnel-make-xinjiang-desert-bloom

Duarah, Ch. K. (2014). India gives green light to build country's largest dam. The third pole.net (29 de septiembre). Recuperado de https://www.thethirdpole.net/en/2014/09/29/indiagives-green-light-to-build-countrys-largest-dam/

Embajada de la República Popular China en la República Oriental del Uruguay. (2007). Geografía de Tíbet. Recuperado de http://uy.china-embassy.org/esp/ztlm/zgxz/t385970.htm

Fayanás, E. (2010). La crisis del agua en la India. Nueva Tribuna (19 de diciembre). Recuperado de http://www.nuevatribuna.es/articulo/medio-ambiente/la-crisis-del-agua-en-laindia/20110107141748040047.htm

Indian Defense News (2017). China's planning a 1,000km tunnel to divert water away from one of India's largest rivers. Indian Defense News (30 de octubre). Recuperado de http://defencenews.in/article/China\%E2\%80\%99s-planning-a-1,000km-tunnel-todivert-water-away-from-one-of-India\%E2\%80\%99s-largest-rivers-444214

Krishnan, A. (2009). India, China and water security. The Hindu (20 de octubre). Recuperado de http://www.thehindu.com/opinion/op-ed/article36468.ece

Krishnan, A. (2014). China's first dam on Brahmaputra river opens. India Today (24 de noviembre). Recuperado de https://www.indiatoday.in/india/story/chinas-first-dam-onbrahmaputra-opens-228360-2014-11-24

Mingst, K. (2009). El medio ambiente: la protección del espacio de los bienes globales. En Fundamentos de las Relaciones Internacionales (pp.475-497). México, D.F.: Centro de Investigación y Docencia Económicas.

Naciones Unidas. (2017). Población. Recuperado de http://www.un.org/es/sections/issuesdepth/population/index.html

Nieto, N. (2011). La gestión del agua: tensiones globales y latinoamericanas. Política y cultura, (36), 157-176. Recuperado de http://www.scielo.org.mx/scielo.php?pid=S018877422011000200007\&script=sci_arttext

Rahman, M. Z. (2016). China and India's race to dam the Brahmaputra river puts the Himalayas at risk. The Conversation (26 de septiembre). Recuperado de http://theconversation.com/china-and-indias-race-to-dam-the-brahmaputra-riverputs-the-himalayas-at-risk-65496 
Tenzin, P. (29 de julio de 2015). China, India y agua a través del Himalaya. The Strategist. Recuperado de https://www.aspistrategist.org.au/china-india-and-water-acrossthe-himalayas/ 